\title{
Systematic review of curative effect between laparoscopic and open repair for perforated gastroduodenal ulcer.
}

\author{
Hu Zhang ${ }^{*}$, Jie Chen ${ }^{2}$, Ying-jun $\mathrm{Li}^{1}$ \\ ${ }^{1}$ Department of General Surgery, Xin Tai People's Hospital, Xintai, Shandong Province, PR China \\ ${ }^{2}$ Department of Intensive Care Unit, Xin Tai People's Hospital, Xintai, Shandong Province, PR China
}

\begin{abstract}
Background and objectives:The effectiveness and safety of laparoscopic operation for perforated gastroduodenal ulcer remains controversial. To provide the evidence of rational operations for both doctors and patients by systematically reviewing the curative effect of laparoscopic and open repair for perforated gastroduodenal ulcer.

Methods: The Randomized Controlled Trials (RCTs) about the curative effect of laparoscopic surgery and open repair for perforated gastroduodenal ulcer were electronically searched from the Cochrane Library, PubMed, China National Knowledge Infrastructure (CNKI), International Statistical Institute (ISI). The standard of literature enrolment and exclusion was made, according to which the literatures were selected. Jadad scale was used to evaluate the chosen study. Data were extracted from these trials and data meta-analysis was performed by RevMan 5.2 software.

Results: Thirteen RCTs involving one thousand and eighteen patients were included (505 patients in the laparoscopic repair group and 513 patients in the open repair group). Meta-analysis showed that compared with conventional open repair group, laparoscopic repair group could reduce the intraoperative blood $(\mathrm{P}<0.00001)$ the postoperative time of recovery of intestinal peristalsis $(\mathrm{P}<0.00001)$, the off-bed time $(\mathrm{P}<0.00001)$, the use of analgesia after operation $(\mathrm{P}=0.0002)$, the chance of wound infection after operation $(\mathbf{P}<\mathbf{0 . 0 0 0 0 1})$, the ileus after operation $(\mathbf{P}=\mathbf{0 . 0 2})$, the postoperation hospital stay $(\mathrm{P}<0.00001)$. But there was no statistically significant difference in the other curative effect between the two groups, including the operation time $(P=0.49)$, pneumonia after operation $(P=0.68)$, the abdominal abscess after operation $(P=0.07)$, death after operation $(P=0.20)$, the total expense of hospital $(P=0.21)$. Conclusion: The overall curative effect of laparoscopic repair group in the treatment of perforated gastroduodenal ulcer is better than that of conventional open repair group. Laparoscopic repair for perforated gastroduodenal ulcer is an acceptable alternative.
\end{abstract}

Keywords: Perforated gastroduodenal ulcer, Laparoscopy, Curative effect, Meta- analysis, System review.

Accepted on June 18, 2018

\section{Introduction}

Perforated gastroduodenal ulcer is one of the common acute abdomens that is treated by surgical, and conventional open repair is an effective method for treatment of perforated gastroduodenal ulcer. Perforated gastroduodenal ulcer is a frequent emergency condition world-wide with associated mortality up to $30 \%$. Tachycardia and abdominal tenderness with rigidity are common clinical signs. Laparoscopic repair for perforated gastroduodenal ulcer was first reported in 1989 by the Mouret [1]. Perforated gastroduodenal ulcer presents as an acute abdominal condition, with localized or generalized peritonitis and a high risk for developing sepsis and death. Early diagnosis is essential, and imaging has an important role in diagnosis, as does early resuscitation including administration of antibiotics. Appropriate risk-assessment and selection of therapeutic alternatives becomes important to address the risk for morbidity and mortality. We are all known that domestic and foreign doctors take more and more attention to the laparoscopic technology for its small trauma, short operation time and quick recovery, and so on. After more than twenty years of development, various laparoscopic surgical operations have carried out both at home and abroad, and laparoscopic operation has been gradually matured in the treatment of patients with perforated gastroduodenal ulcer, but compared to the open operation, there are more controversies that whether the effectiveness and safety of laparoscopic operation for perforated gastroduodenal ulcer has the existence of incomplete treatment, recurrence, and so on.

In this study, our aim is to provide the objective and reliable evidence for the treatment of perforated gastroduodenal ulcer by clinical effectiveness and safety of patients between 
laparoscopic and open repair for perforated gastroduodenal ulcer.

\section{Methods}

The included standard experiments were randomized controlled trials. The object of study was patients with perforated gastroduodenal ulcer. The articles were all related to laparoscopic and open repair in the treatment of perforated gastroduodenal ulcer. The observed indexes including the operation time, the intraoperative blood, the postoperative time of recovery of intestinal peristalsis, the off-bed time, the use of analgesia after operation, the total expense of hospital, the postoperation hospital stay, pneumonia after operation, the chance of wound infection after operation, the ileus after operation, the abdominal abscess after operation, death after operation.

\section{Literature exclusion criteria}

Non-experimental design of randomized controlled trials. The study included patients with non-perforated gastroduodenal ulcer. Not comparing two surgical. The information is incomplete. Published data was repetitive.

\section{Data retrieval}

We are strict in the eligible literature with included standard and exclusion standard by reading the title and abstract. Information retrieval comprehensively were searched published from January 1979 to December 2013 and compared the efficacy of the patient by laparoscopic and open repair for perforated gastroduodenal ulcer in randomized controlled studies. Specific retrieval methods: We searched Cochrane Library, PubMed (1998.01 2013.12), CNKI (1979.01 2013.12), ISI (1998.01 2013.12), Chinese key words of "random, laparoscopy, laparotomy, gastric ulcer perforation, efficacy, systematic reviews, meta-analysis", English key words of "random, randomized controlled trials, laparoscopic, laparoscopy, open repair, perforated gastroduodenal ulcer, curative effect, system review, metaanalysis", search strategy to make the appropriate adjustments in each database. By reading the title and summary of the literature on the possible qualifiers read more strictly in accordance with the inclusion and exclusion criteria.

\section{Quality assessment of selected literature}

Quality assessment of selected literature used the description of the concealment and blinding from RCT quality standards of Cochrane Reviewer' Handbook 5.2 [2]. It includes the random sequence generation, allocation concealment, blinding of participants and personnel, binding of outcome assessment, incomplete outcome data, selective reporting. The study explained is the high quality if these indicators are all in line, or it is the possibility of generating a bias.

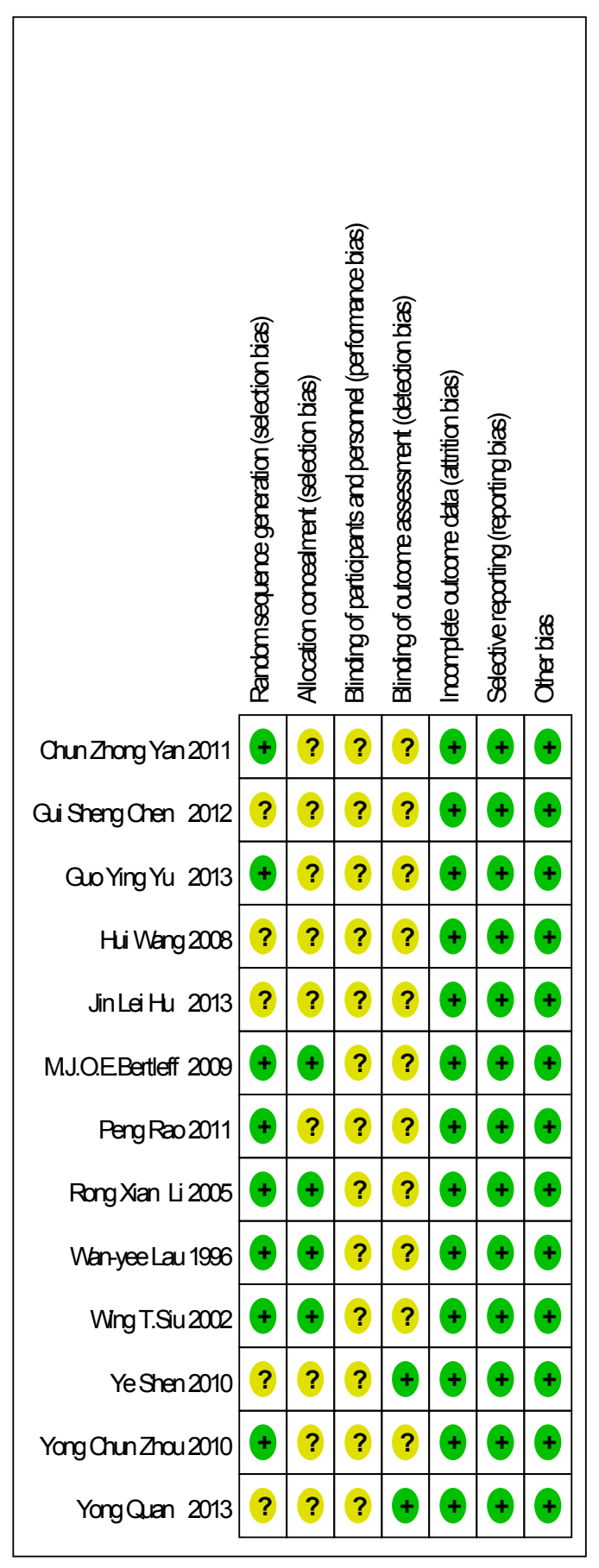

Figure 1. Risk of bias summary: review authors' judgements about each methodological of item presented as percentages across all included studies. (Low risk; Unclear risk; high risk).

\section{Data extraction}

The basic data, the first author, year of publication, operation mode, the number of cases.

The curative effect observation index The index includes the operate time, intraoperative blood ,postoperative time of recovery of intestinal peristalsis, off-bed time, use of analgesia after operation, pneumonia after operation, wound infection after operation, ileus after operation, abdominal abscess after 
operation, death after operation, the total expense of hospital, postoperation hospital stay.

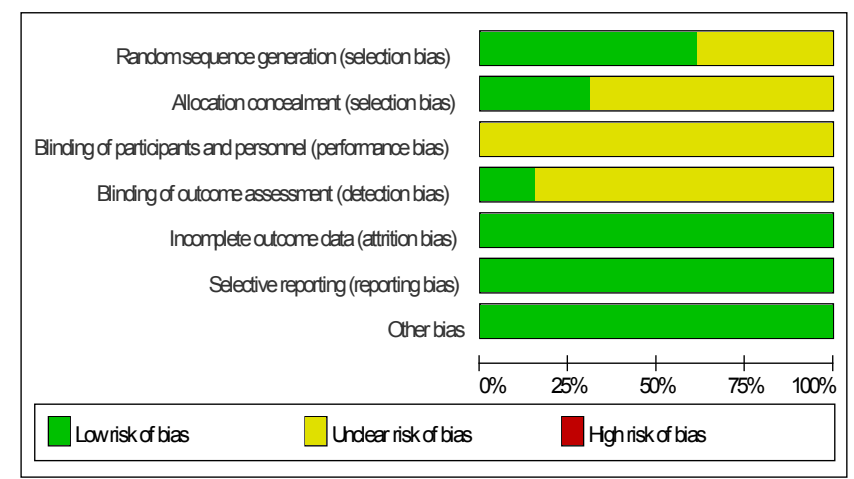

Figure 2. Risk of bias graph: review authors' judgements about each risk of item presented as percentages across all included studies.

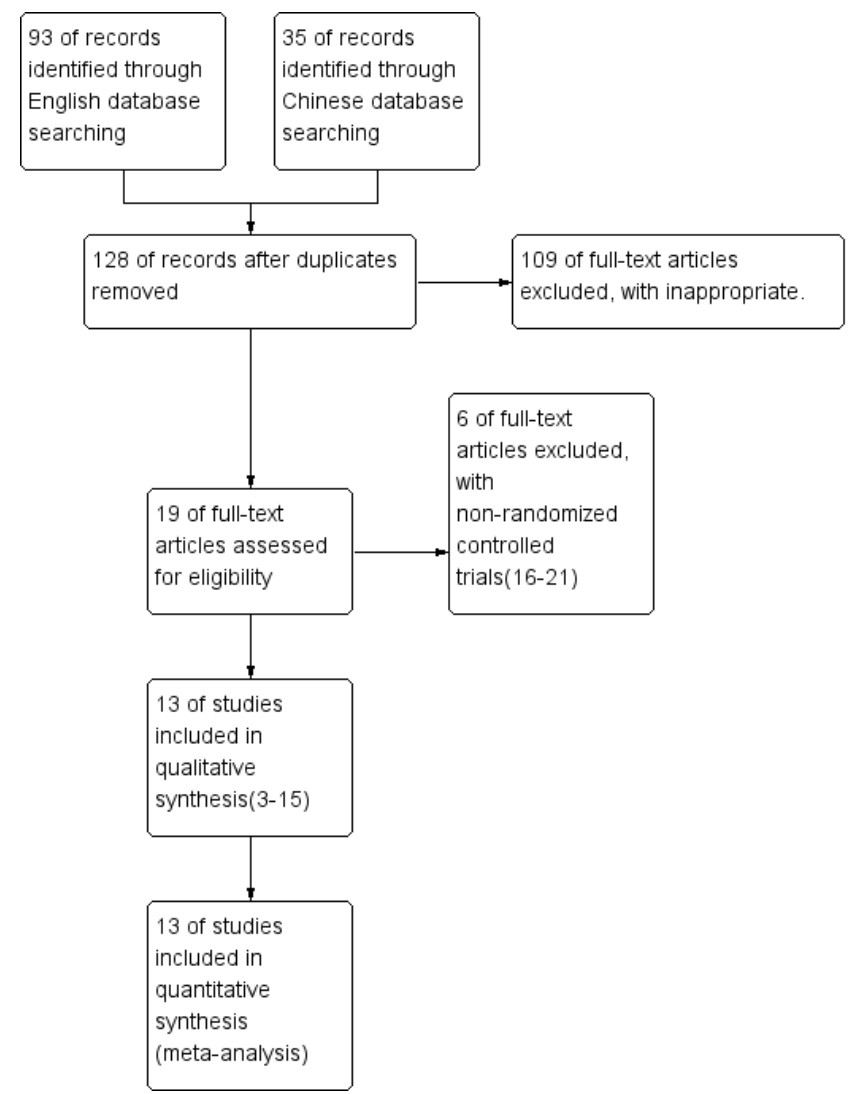

Figure 3. Flow diagram of the literature search and trials selection process.

\section{Statistical processing}

RevMan 5.2 software package are used to the statistical data extracted. The relative risk (Risk Ratio, RR) and 95\% Confidence Intervals (confidence interval, CI) are used to the binary data, and the standardized mean difference (Standardized Mean Difference, SMD) and 95\% CI are used to continuous data, $\alpha=0.05$ is as a test level in the case described in no special. Funnel plots are used to assess whether there is the publication bias.

\section{Result}

There are thirteen randomized controlled studies [3-15] are analysed to selected literature quality evaluation and basic data, including four high quality studies, nine secondary quality studies. The random sequence generation of four studies are appropriate, and another nine is not clear (Figure 1) [16-19]. The number of cases was one thousand and eighteen cases, including five hundred and five cases of laparoscopic surgery and five hundred and thirteen cases of laparotomy (Figure 2). Flow diagram of the literature search and trials selection process was seen from Figure 3 [20,21].

\section{Comparison of the efficacy and safety}

The operative time: There were thirteen studies which were related to the comparison of the operation time between laparoscopic and open repair for perforated gastroduodenal ulcer. The difference was statistically significant in the difference test for heterogeneity between studies $(\mathrm{P}<0.00001$, $\mathrm{I}^{2}=94 \%$ ), therefore, we used a random effects model to analysis it. Meta-analysis showed that the difference was not statistically significant between the laparoscopic and open repair $(\mathrm{SMD}=3.39,95 \% \mathrm{CI}(-6.18,12.95), \mathrm{P}=0.49)$ (Figure 4).

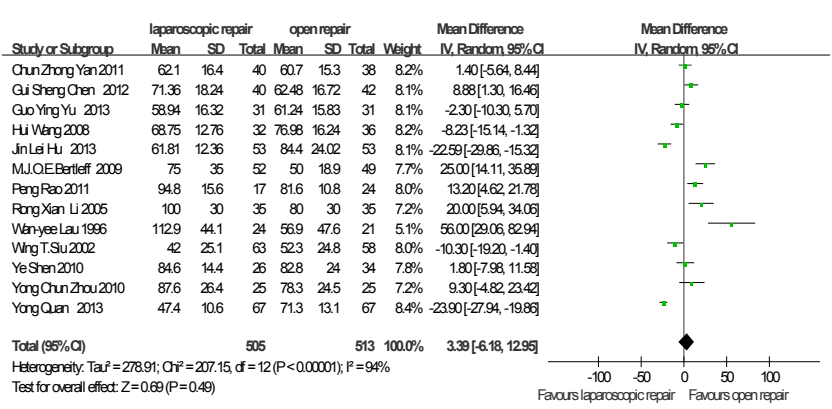

Figure 4. The operate time between laparoscopic and open repair for perforated gastroduodenal ulcer.

The intraoperative blood: There were eight studies which were related to the comparison of the intraoperative blood between laparoscopic and open repair for perforated gastroduodenal ulcer. The difference was statistically significant in the difference test for heterogeneity between studies $\left(\mathrm{P}<0.00001, \mathrm{I}^{2}=97 \%\right)$, therefore, we used a random effects model to analysis it. Meta-analysis showed that the difference was statistically significant between the laparoscopic and open repair $(\mathrm{SMD}=-39.73,95 \% \mathrm{CI}(-50.38$, -29.07), $\mathrm{P}<0.00001$ ) (Figure 5).

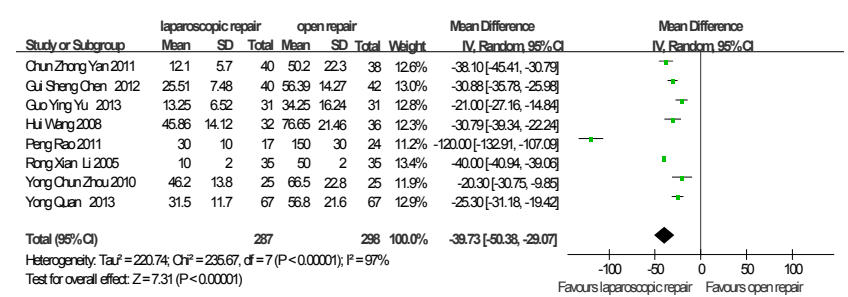

Figure 5. The intraoperative blood between laparoscopic and open repair for perforated gastroduodenal ulcer. 
The postoperative time of recovery of intestinal peristalsis: there were eight studies which were related to the comparison of the postoperative time of recovery of intestinal peristalsis between laparoscopic and open repair for perforated gastroduodenal ulcer. The difference was statistically significant in the difference test for heterogeneity between studies $\left(\mathrm{P}<0.0003, \mathrm{I}^{2}=75 \%\right)$, therefore, we used a random effects model to analysis it. Meta-analysis showed that the difference was statistically significant between the laparoscopic and open repair $(\mathrm{SMD}=-1.32$, 95\% CI $(-1.54$, -1.10), $\mathrm{P}<0.00001$ ) (Figure 6).

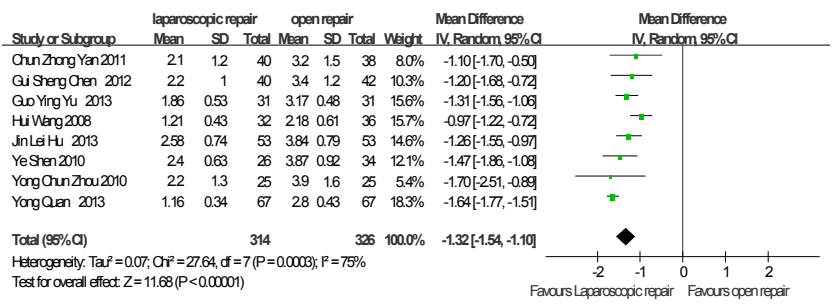

Figure 6. The postoperative time of recovery of intestinal peristalsis between laparoscopic and open repair for perforated gastroduodenal ulcer.

The off-bed time: There were two studies which were related to the comparison of the off-bed time between laparoscopic and open repair for perforated gastroduodenal ulcer. The difference was statistically significant in the difference test for heterogeneity between studies $\left(\mathrm{P}<0.00001, \mathrm{I}^{2}=97 \%\right)$, therefore, we used a random effects model to analysis it. Meta-analysis showed that the difference was statistically significant between the laparoscopic and open repair $(\mathrm{SMD}=-19.33,95 \% \mathrm{CI}$ (-27.77, -10.89), $\mathrm{P}<0.00001)$ (Figure 7).

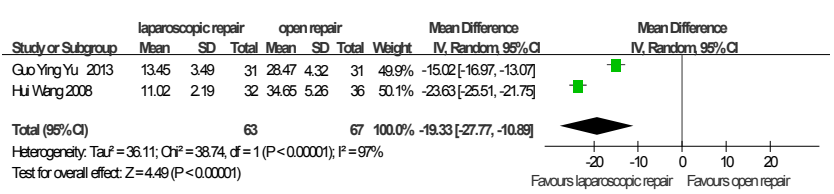

Figure 7. The off-bed time between laparoscopic and open repair for perforated gastroduodenal ulcer.

The use of analgesia after operation: there were five studies which were related to the comparison of the use of analgesia after operation between laparoscopic and open repair for perforated gastroduodenal ulcer. The difference was statistically significant in the difference test for heterogeneity between studies $\left(\mathrm{P}=0.04, \mathrm{I}^{2}=59 \%\right)$, therefore, we used a random effects model to analysis it. Meta-analysis showed that the difference was statistically significant between the laparoscopic and open repair $(\mathrm{SMD}=0.07,95 \% \mathrm{CI}(0.02,0.28)$, $\mathrm{P}=0.0002)$ (Figure 8).

Pneumonia after operation: There were six studies which were related to the comparison of the pneumonia after operation between laparoscopic and open repair for perforated gastroduodenal ulcer. The difference was no statistically significant in the difference test for heterogeneity between studies $\left(\mathrm{P}=0.87, \mathrm{I}^{2}=0 \%\right)$, therefore, we used a fixed effects model to analysis it. Meta-analysis showed that the difference was no statistically significant between the laparoscopic and open repair $(\mathrm{SMD}=0.84,95 \% \mathrm{CI}(0.37,1.90), \mathrm{P}=0.68)$ (Figure 9).

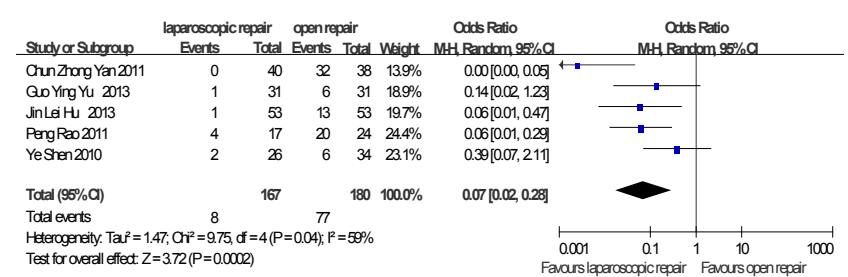

Figure 8. The use of analgesia after operation between laparoscopic and open repair for perforated gastroduodenal ulcer.

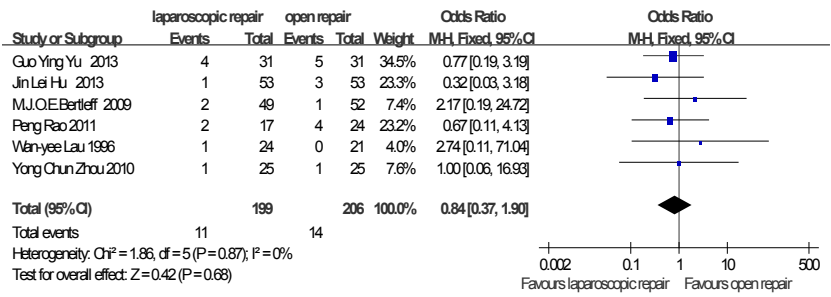

Figure 9. Pneumonia after operation between laparoscopic and open repair for perforated gastroduodenal ulcer.

Wound infection after operation: There were eleven studies which were related to the comparison of the wound infection after operation between laparoscopic and open repair for perforated gastroduodenal ulcer. The difference was no statistically significant in the difference test for heterogeneity between studies $\left(\mathrm{P}=0.90, \mathrm{I}^{2}=0 \%\right)$, therefore, we used a fixed effects model to analysis it. Meta-analysis showed that the difference was statistically significant between the laparoscopic and open repair $(\mathrm{SMD}=0.19,95 \% \mathrm{CI}(0.09,0.39)$, $\mathrm{P}<0.00001$ ) (Figure 10).

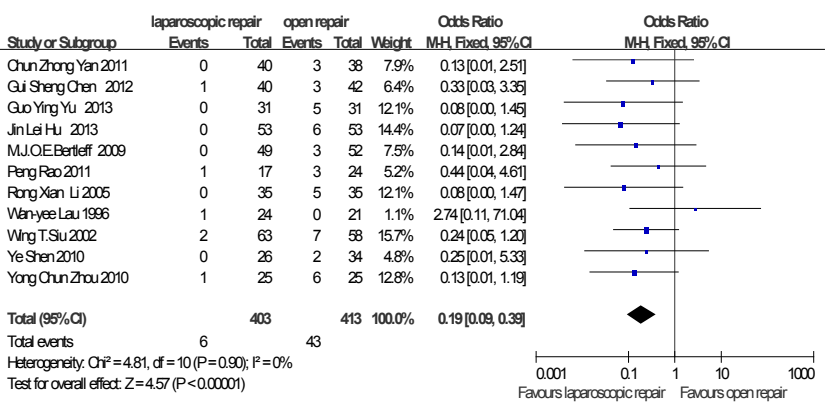

Figure 10. Wound infection after operation between laparoscopic and open repair for perforated gastroduodenal ulcer.

Ileus after operation: There were eight studies which were related to the comparison of the Ileus after operation between laparoscopic and open repair for perforated gastroduodenal ulcer. The difference was no statistically significant in the difference test for heterogeneity between studies $(\mathrm{P}=1.00$, $\mathrm{I}^{2}=0 \%$ ), therefore, we used a fixed effects model to analysis it. Meta-analysis showed that the difference was statistically significant between the laparoscopic and open repair $(\mathrm{SMD}=0.30,95 \% \mathrm{CI}(0.11,0.79), \mathrm{P}=0.02)$ (Figure 11). 


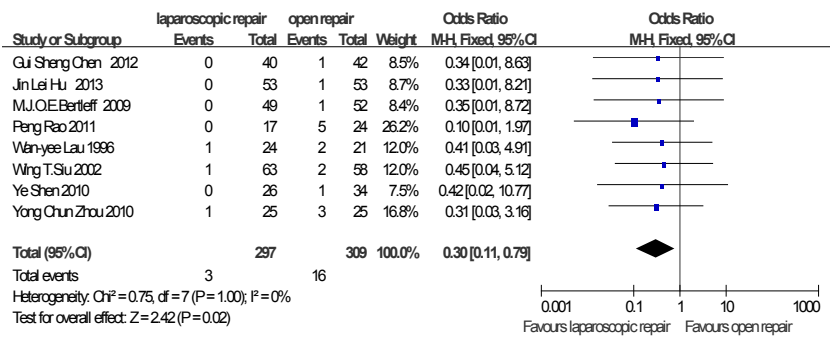

Figure 11. Ileus after operation between laparoscopic and open repair for perforated gastroduodenal ulcer.

Abdominal abscess after operation: There were six studies which were related to the comparison of the abdominal abscess after operation between laparoscopic and open repair for perforated gastroduodenal ulcer. The difference was no statistically significant in the difference test for heterogeneity between studies $\left(\mathrm{P}=0.66, \mathrm{I}^{2}=0 \%\right)$, therefore, we used a fixed effects model to analysis it. Meta-analysis showed that the difference was no statistically significant between the laparoscopic and open repair $(\mathrm{SMD}=0.42,95 \% \mathrm{CI}(0.16,1.07)$, $\mathrm{P}=0.07$ ) (Figure 12).

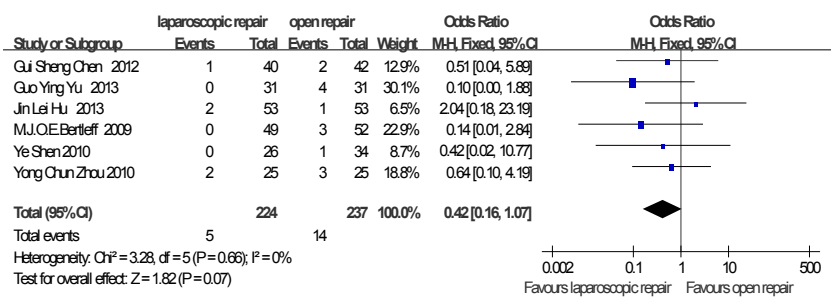

Figure 12. Abdominal abscess after operation between laparoscopic and open repair for perforated gastroduodenal ulcer.

Death after operation: There were two studies which were related to the comparison of the death after operation between laparoscopic and open repair for perforated gastroduodenal ulcer. The difference was no statistically significant in the difference test for heterogeneity between studies $(\mathrm{P}=0.98$, $\mathrm{I}^{2}=0 \%$ ), therefore, we used a fixed effects model to analysis it. Meta-analysis showed that the difference was no statistically significant between the laparoscopic and open repair $(\mathrm{SMD}=0.29,95 \% \mathrm{CI}(0.04,1.89), \mathrm{P}=0.20)$ (Figure 13).

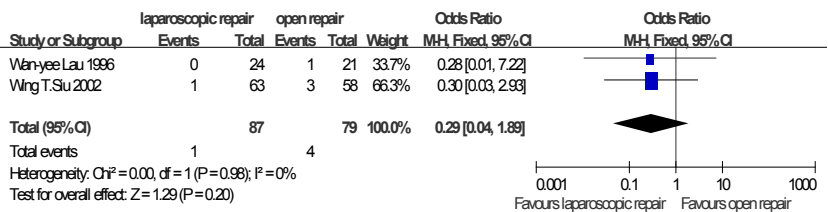

Figure 13. Death after operation between laparoscopic and open repair for perforated gastroduodenal ulcer.

The total expense of hospital: There were four studies which were related to the comparison of the total expense of hospital between laparoscopic and open repair for perforated gastroduodenal ulcer. The difference was statistically significant in the difference test for heterogeneity between studies $\left(\mathrm{P}<0.00001, \mathrm{I}^{2}=98 \%\right)$, therefore, we used a random effects model to analysis it. Meta-analysis showed that the difference was no statistically significant between the laparoscopic and open repair $(\mathrm{SMD}=678.20,95 \% \mathrm{CI}(-375.13$, 1731.54), $\mathrm{P}=0.21$ ) (Figure 14).

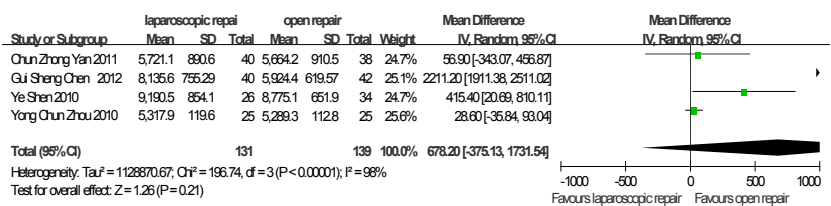

Figure 14. The total expense of hospital between laparoscopic and open repair for perforated gastroduodenal ulcer.

The postoperation hospital stay: There were eleven studies which were related to the comparison of the postoperation hospital stay between laparoscopic and open repair for perforated gastroduodenal ulcer. The difference was statistically significant in the difference test for heterogeneity between studies $\left(\mathrm{P}<0.00001, \mathrm{I}^{2}=77 \%\right)$, therefore, we used a random effects model to analysis it. Meta-analysis showed that the difference was statistically significant between the laparoscopic and open repair $(\mathrm{SMD}=-3.35,95 \% \mathrm{CI}(-4.09$, 2.60), $\mathrm{P}<0.00001$ ) (Figure 15).

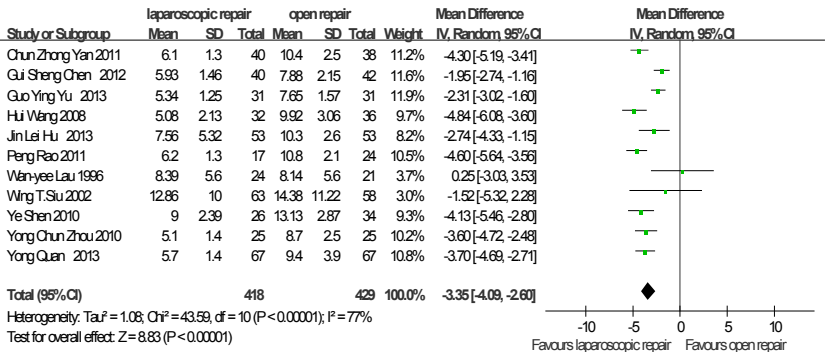

Figure 15. The postoperation hospital stays between laparoscopic and open repair for perforated gastroduodenal ulcer.

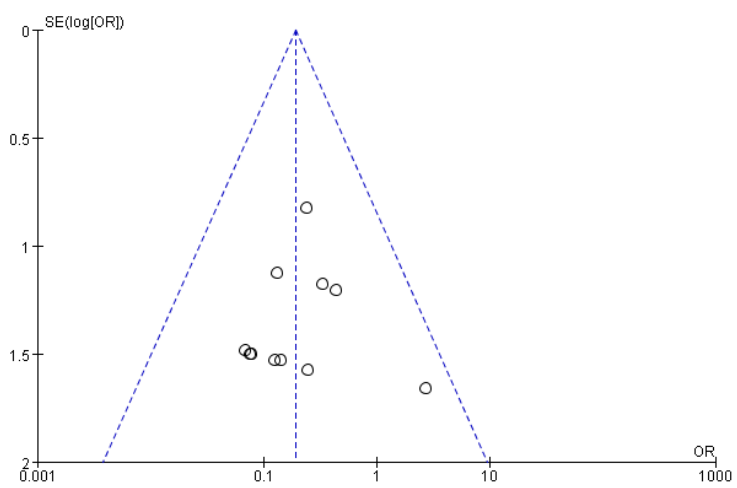

Figure 16. Changes in the funnel plot.

Publication bias: The study includes thirteen articles. Begg's funnel plot was performed to assess the publication bias. The results showed, funnel plots of observation indexes are symmetry basically. The shape of funnel plots did not reveal any evidence of obvious asymmetry in all comparison models. The results did not show any evidence of publication bias. The detailed data were present in Figure 16. 


\section{Discussion}

\section{Basic characteristics and quality analysis}

Thirteen randomized controlled trials were included in the meta-analysis. The number of cases from the repair of perforated gastroduodenal ulcer in patients was one thousand and eighteen cases, including 505 laparoscopic operations, 513 open repairs. Two groups are comparable in the sex and age.

Perforation of gastroduodenal is the common complications of the ulcer of upper digestive tract.

Simple suture repaired operation, which is also reliably effective, is the ideal treatment of perforated gastroduodenal ulcer. The laparoscopic exploration is used to the atypical clinical manifestation, no previous history of peptic ulcer, undiagnosed before operation, because it can diagnose clearly, but also repair the operation. Therefore, laparoscopic surgery in diagnosis of acute abdomen is one of the new models of diagnosis, exploration and treatment. The operating time was longer and recurrent leakage was higher in laparoscopic group. However, the laparoscopic group also showed less postoperative pain and a shorter hospital stay. Furthermore, the laparoscopic treatment is also associated with equivalent costs compared with the open surgery as it reduces duration of hospital stays [22]. Laparoscopic repair techniques mirror techniques of open surgery and in particular suture less techniques are more prominently described. This may in part due to training in intra-corporeal knotting skills. Laparoscopic gastric ulcer perforation repair has the following advantages compared to the open one assist to diagnosis, and to avoid the blind laparotomy. We can accurately find the lesion site, and to avoid the laparotomy, by the laparoscope for diagnostic testing for patients with acute abdomen. It is also conducive to select the correct incision to avoid replacing incision laparotomy and prolongs the predicament. Laparoscopic repair has the little operation scar, smaller impact to the organism environmental, less postoperative complications, faster recovery. The hands were not got into the abdominal cavity with laparoscopic repair. Abdominal operation was gentle, and the abdominal cavity was in the closed state. So the organ was not exposed in the air, and had the light gut stimulation, and laparoscopic repair had the early postoperative ambulation, therefore, the function of gastrointestinal peristalsis could be recovered quickly, and to reduce the occurrence of postoperative intestinal adhesion and inflammatory intestinal obstruction. Laparoscopic operation had the more clear surgical field, and the more completely peritoneal lavage, so it could reduce the occurrence of residual abscess under diaphragm and in the abdominal cavity.

Not all the patients are suitable for laparoscopic operation, because of its particularity. In order to avoid laparotomy operation, I think that the indications of laparoscopic repair for the perforated gastroduodenal ulcer, general condition is good, without serious heart, lung disease. The time of cute perforation was less than $24 \mathrm{~h}$. Without pyloric obstruction, hemorrhage, and transformation, the diameter of ulcer perforation is less than $1 \mathrm{~cm}$. Without the history of supreme abdominal operation, the treatment of peptic ulcer perforation repair was various. Repair was simple and had small risk, so it was still the main treatment of ulcerative perforation.

In short, perforated peptic ulcer treatment is associated with a significant postoperative morbidity and mortality regardless of whether laparoscopic or open repair is performed [23]. The results of this study showed that compared to the traditional open surgery repair, the laparoscopic repair had the more obvious superiority and it was worthy for the clinical promotion for acute perforation of gastroduodenal ulcer patients.

\section{References}

1. Mouret P, François Y, Vignal J, Barth X, Lombard-Platet R. Laparoscopic treatment of perforated peptic ulcer. Br J Surg 1990; 77: 1006.

2. Higgins JPT, Green S. Assessing risk of bias in included studies. Cochrane Handbook for Systematic Reviews of Interventions Cochrane Collaboration 2013.

3. Chun-zhong Y, Chao-hong C, Zhao Y. A comparative study between laparoscopic and conventional open repair in the perforated gastric ulcer surgery. ZH J J Traumatic 2011; 16: 54-55.

4. Gui-sheng C. A comparative study between laparoscopic and open repair in the perforated gastric ulcer surgery. J Minim Inv Med 2012; 7: 551-552.

5. Guo y, Yong-ming C. Comparative study of laparoscopy and mini-incision laparotomy in the treatment of perforated gastroduodenal ulcer. J Laparosc Surg 2013; 18: 425-427.

6. Hui W, Zheng-ping C, Cheng H. Comparative study of laparoscopic and conventional open repair in the perforated gastric ulcer surgery. Shandong Med 2008; 48: 92-93.

7. Jin-lei H. The treatment efficacy of two kinds of Surgeries in the gastric ulcer perforation. Mod J Integr Trad Chinese West Med 2013; 22: 2076-2077.

8. Bertleff MJ, Halm JA, Bemelman WA, van der Ham AC, van der Harst E, Oei HI, Smulders JF, Steyerberg EW, Lange JF. Randomized clinical trial of laparoscopic versus open repair of the perforated peptic ulcer: the LAMA Trial. World J Surg 2009; 33: 1368-1373.

9. Peng R, Jia-qing C, Zhi-yong Z. Comparative study between laparoscopic and conventional open in elderly patients with gastroduodenal perforation repair. Pract Clin Med 2011; 12: 37-38.

10. Rong-xian L, Xiu-juan S, Bo Z. The efficacy comparison of laparoscopic surgery and open surgery in gastroduodenal ulcer perforation repair. J Xinxiang Med Coll 2005; 22: 249-250.

11. Lau WY, Leung KL, Kwong KH. A randomized study comparing laparoscopic versus open repair of perforated peptic ulcer using suture or suture less technique. Ann Surg 1996; 224: 131-138. 
12. Siu WT, Leong HT, Law BK. Laparoscopic repair for perforated peptic ulcer: a randomized controlled trial. Ann Surg 2002; 235: 313-319.

13. Ye S, Jian-ping G, Lian-ming Z. The efficacy study between laparoscopic and open gastric ulcer perforation repair surgery. Chongqing Med J 2010; 39: 1890-1891.

14. Yong-chun Z, Jian-bao Y. Comparison of the effects of laparoscopy and open surgery for gastroduodenal ulcer perforation. J Minim Inv Med 2010; 5: 571-573.

15. Yong Q, Yong Y, Li Z. A comparative effect between open surgery and laparoscopic surgery for gastric and duodenal perforation. J Minim Inv Med 2013; 11: 8-9.

16. Navez B, Navez J. Laparoscopy in the acute abdomen. Best Pract Res Clin Gastroenterol 2014; 28: 3-17.

17. Søreide K, Thorsen K, Søreide JA. Strategies to improve the outcome of emergency surgery for perforated peptic ulcer. Br J Surg 2014; 101: e51-64.

18. Botianu A, Matei D, Tantau M. Mortality and need of surgical treatment in acute upper gastrointestinal bleeding: a one year study in a tertiary center with a 24 hours/day-7 days/week endoscopy call. Has anything changed? Chirurgia (Bucur) 2013; 108: 312-318.

19. Antoniou SA, Antoniou GA, Koch OO, Pointner R, Granderath FA. Meta-analysis of laparoscopic versus open repair of perforated peptic ulcer. JSLS 2013; 17: 15-22.
20. Leontiadis GI, Sreedharan A, Dorward S. Systematic reviews of the clinical effectiveness and cost-effectiveness of proton pump inhibitors in acute upper gastrointestinal bleeding. Health Technol Assess 2007; 11: 1-164.

21. Lau JY, Lo SY, Ng EK. A randomized comparison of acute phase response and endotoxemia in patients with perforated peptic ulcers receiving laparoscopic or open patch repair. Am J Surg 1998; 175: 325-327.

22. Wright GP, Davis AT, Koehler TJ, Scheeres DE. Costefficiency and outcomes in the treatment of perforated peptic ulcer disease: laparoscopic versus open approach. Surgery 2014; 156: 1003-1007.

23. Lunevicius R, Morkevicius M. Systematic review comparing laparoscopic and open repair for perforated peptic ulcer. Br J Surg 2005; 92: 1195-1207.

\section{${ }^{*}$ Correspondence to}

$\mathrm{Hu}$ Zhang

Department of General Surgery

Xin Tai People's Hospital

PR China 